\title{
Minimal descriptors for characterization and evaluation of Jatropha curcas L. germplasm for utilization in crop improvement
}

\author{
Neelam Sunil ${ }^{a}$, Vinod Kumar $^{b}$, Mulpuri Sujatha ${ }^{c, *}$, Gandhe Rajeswara Rao ${ }^{d}$, \\ Kodeboyina Siva Varaprasad ${ }^{\mathrm{c}}$ \\ ${ }^{a}$ National Bureau of Plant Genetic Resources, Regional Station, Rajendranagar, Hyderabad 500 030, India \\ b International Crop Research Institute for Semi-Arid Tropics, Patancheru, Hyderabad 502 324, India \\ ${ }^{c}$ Directorate of Oilseeds Research, Rajendranagar, Hyderabad 500 030, India \\ ${ }^{d}$ Central Research Institute for Dryland Agriculture, Santhoshnagar, Hyderabad 500 059, India
}

\section{A R T I C L E I N F O}

\section{Article history:}

Received 19 July 2011

Received in revised form

12 November 2012

Accepted 20 November 2012

Available online

Keywords:

Characterization

Descriptors

Evaluation

Germplasm

Jatropha

Variability

\begin{abstract}
A B S T R A C T
Jatropha curcas germplasm collected from peninsular region of India as well as germplasm augmented from various parts of the country was characterized for various agromorphological traits at 3 locations for 3 years. Variability was evident for 38 traits which included both qualitative and quantitative traits. Important yield influencing traits such as plant canopy, branching habit, number of primary branches, peduncle branching, peduncle length, inflorescence compactness, flower ratio, inflorescence abundance, flowering, fruits per cluster, 100-seed weight and oil content showed a wide range of variability in the germplasm under study. Number of leaf lobes also showed variation and accordingly were categorised as $0-2,3-5,>6$. The branching pattern varied widely and has been categorised as basal, intermediate, top and entire. The male to female flower ratio ranged from 10:1 to $>20: 1$, and was categorized into three categories as 10:1, 11-20:1 and $>20: 1$. The seed oil content which is of commercial importance in J. curcas also exhibited wide variability ranging from 17.5 to $41.6 \%$ and the descriptor has been categorized accordingly as $0-20,21-30,30-40$ and $\geq 40 \%$. Based on the variability observed in the traits, a set of 38 minimal descriptors has been suggested for characterization and evaluation of Jatropha.
\end{abstract}

(c) 2012 Elsevier Ltd. All rights reserved.

\section{Introduction}

Jatropha has adapted itself to various eco-geographical zones in India and it has since accumulated lot of variability over many decades. Documentation of the variation in morphological traits is necessary to effectively tap the available diversity in the crop improvement programmes. In furtherance of this objective, an attempt was made to study the crop in detail for various traits under uniform agro-climatic conditions. Based on such a study, the minimal descriptors have been developed and a simple working botanical classification has been provided for convenience of researchers working on Jatropha curcas. The consequent descriptor and descriptor states is an initial step and not an exhaustive one as there exists still an unexplored and untapped genetic potential for the crop at large. The minimal descriptor list helps in characterization of germplasm for development of a dataset of the collected material for utilization in the J. curcas improvement programmes.

\footnotetext{
* Corresponding author. Tel.: +91 40 24015345; fax: +91 4024017969.

E-mail address: mulpurisujata@yahoo.com (M. Sujatha). 


\subsection{Challenges in Jatropha germplasm collection}

Germplasm collection of Jatropha has its own set of challenges and since the species is not native to India, lack of information and experience in identification of the areas of its availability are the major limitations. The plant produces seed throughout the year which results in collection of small quantity of seeds. Besides, fruiting coincides with cool and wet weather which favours the growth of moulds on the collected seeds and often results in delayed maturation. The plants differ in maturity period which affects collection and choice of the explorer. The pods persist for a long period on the plant after maturity which frequently results in collection of remnants of previous season pods leading to poor storage, viability and erroneous oil estimation. During exploration, harvesting of pods is a challenge as the plants are found on periphery of wet land as hedge plants along cultivated fields and along the scrub vegetation besides, lack of improvised harvesting and processing equipment. Plant latex is a major hindrance in seed collection as it leaves a stubborn stain. In villages, uniform plant types were observed as the plants were raised from cuttings and hence, it was advisable to collect $2-3$ accessions from a particular village ecosystem as it represents the variation existing there. The common feature observed in surveyed areas was the wide spread infection of mosaic virus among the plant populations.

\section{Materials and methods}

The J. curcas germplasm used for establishing minimal descriptors comprised of accessions from diverse agroecological regions of the country ranging from Uttarakhand, Rajasthan, Chattisgarh, Andhra Pradesh, Tamil Nadu and Kerala [1]. The germplasm was raised at the experimental station of the NBPGR Regional station, Hyderabad, India under uniform soil conditions and subjected to uniform package of practices. Three-year-old plantations, spaced at $2 \times 2 \mathrm{~m}$ in an Augmented Block Design without any interventions like pruning were characterized. The material was replicated at two other centres viz., Acharya N.G.Ranga Agricultural University (ANGRAU), Rajendranagar, Hyderabad and Central Research Institute for Dryland Agriculture (CRIDA), Hyderabad, India for documentation of the characteristics for 3 consecutive years. An initial dose of $2 \mathrm{~kg}$ of farm yard manure (FYM) per pit and recommended fertilizer doses viz. $5 \mathrm{~g}$ of nitrogen, $10 \mathrm{~g}$ of phosphorus and $8 \mathrm{~g}$ of potash fertilizers were applied at the time of transplantation. The plants were given irrigation as and when required. The experimental site is characterised by red sandy loam soils with $\mathrm{pH}$ of 7.2 and located at an altitude of 542 above mean sea level. Mean air temperature ranged from a minimum of $14{ }^{\circ} \mathrm{C}$ (during December and January) to a maximum of $40{ }^{\circ} \mathrm{C}$ (during April and May). The average rainfall ranged between 700 and $800 \mathrm{~mm}$ with maximum rains received from South-West monsoon during the months of June to August. However, occasionally rains in the month of October and November were received due to North-East monsoon. The fruits were harvested at physiological maturity stage (yellow), seed was extracted and shade dried for a week. The oil content was analysed by Soxhlet method, which involved well mixed Jatropha seed (5.0 g) ground and transferred into an extraction thimble and the top portion covered with cotton. This packed thimble was placed in the extraction chamber of SER 148 Solvent Extractor (VELP Scientifica, Italy). Around $70 \mathrm{ml}$ of hexane was taken in the extractor and the temperature of the solvent heating block was adjusted to $130^{\circ} \mathrm{C}$ (Recommended set point for hexane). The thimble was socked in hexane and the solvent was refluxed over a period of $1 \mathrm{~h}$. After $1 \mathrm{~h}$, the thimble was lifted from the solvent and the solvent was allowed to pass through the bed of ground seeds for $15 \mathrm{~min}$. This operation ensures washing of the thimble with fresh solvent. Hexane was distilled off to recover Jatropha oil. A recovery of $1.72 \mathrm{~g}$ corresponds to $34.4 \%$.

Details were documented on 38 growth traits such as, growth habit, plant canopy, leafiness, branching habit and pattern, number of primary branches, stem colour, latex colour, pigmentation of emerging leaves, petiole base pigmentation, leaf blade size, petiole length, leaf colour, number of lobes, phyllotaxy, leaf alignment, peduncle branching, peduncle length, inflorescence position on the branches and compactness, flower colour, flower size, flower ratio, inflorescence, seasonality of flowering, length of fruit stalk, number of fruits per cluster, average no. of seeds per fruit, pod length, pod breadth, pod width, seed length, seed breadth, seed width, 100seed weight (g), seed surface, fruit shape and oil content. During peak flowering period, traits such as the number of inflorescences, type of inflorescence, female:male flower ratio, flower size, etc. were recorded. Branching habit was recorded during the autumn season as the plant sheds its leaves which are convenient to make such observations. Post rainy season prior to the onset of winter season was chosen for recording fruit and associated traits. Other morpho-physiological traits were recorded during peak growth stages of the respective traits. Canon digital SLR (350 D) 10 mega pixel camera was used to take the photographs and wherever necessary standard centimetre scale was used to measure the various traits under study.

\section{Results and discussion}

\subsection{Minimal descriptors developed for characterization and evaluation based on variability observed}

\subsubsection{Growth habit}

The growth habit of accessions under study was recorded on three-year-old plantations raised under uniform agronomic practises, soil and weather conditions (Fig. 1).

1. Shrub $(<5 \mathrm{~m})$

2. Tree $(>5 \mathrm{~m})$

\subsubsection{Plant canopy}

The plant canopy was recorded on three-year-old plantations raised under uniform agronomic practises, soil and weather conditions (Fig. 2).
1. Narrow
2. Intermediate
3. Spreading 


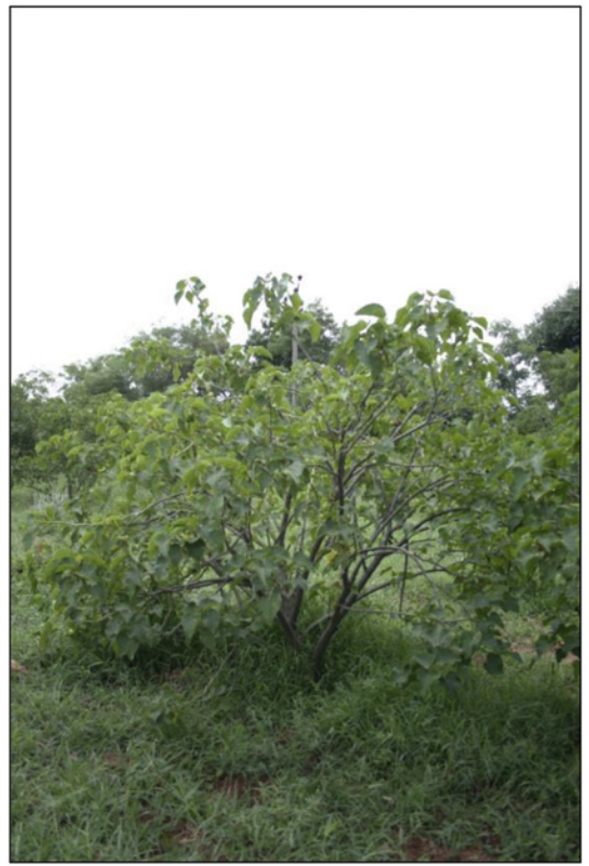

1. Shrub

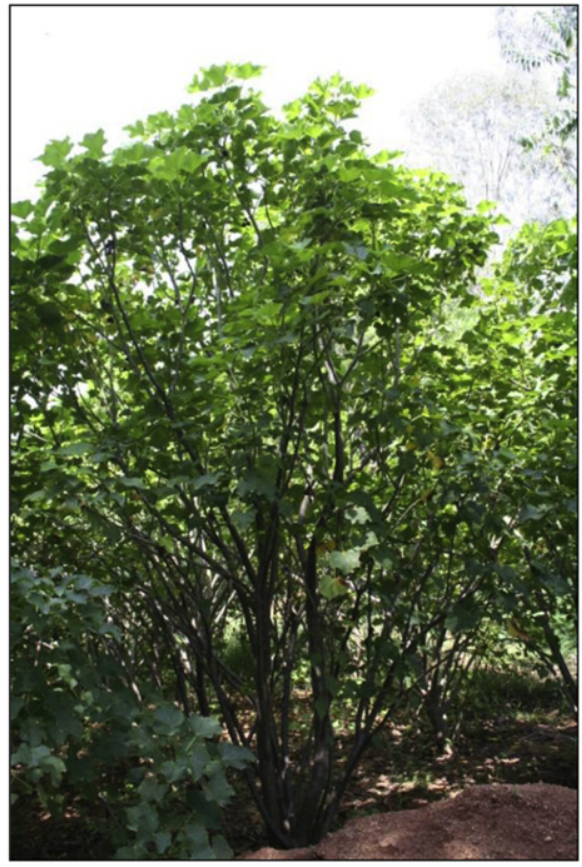

2. Tree

Fig. 1 - Growth habit.

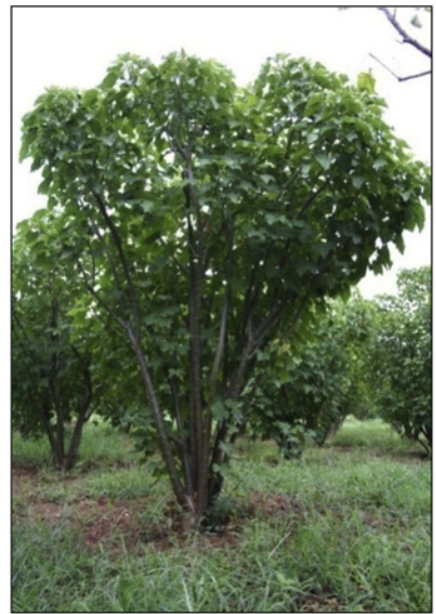

1. Narrow

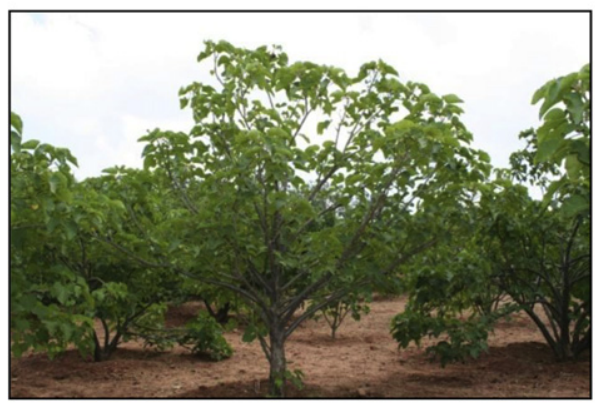

2. Intermediate

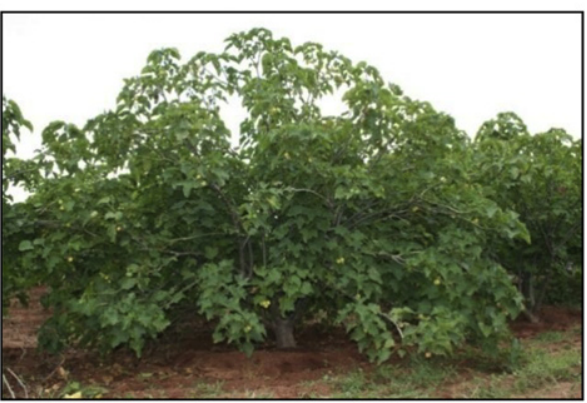

3. Spreading

Fig. 2 - Plant canopy. 


\subsubsection{Branching habit}

The branching habit was recorded on three-year-old plantations raised under uniform agronomic practises, soil and weather conditions.
1. Sparse
2. Intermediate
3. Dense

\subsubsection{Leafiness}

The leafiness of accessions was recorded at peak vegetative stage of the plant (Fig. 3).
1. Abundant
2. Moderate
3. Scanty

\subsubsection{Branching pattern}

The branching pattern was recorded on three-year-old plantations raised under uniform agronomic practises, soil and weather conditions (Fig. 4).
1. Basal
2. Intermediate
3. Top
4. Entire

\subsubsection{Number of primary branches}

The number of primary branches was recorded on three-yearold plantations raised under uniform agronomic practises, soil and weather conditions.
1. $0-4$
2. $5-10$
3. $11-15$
4. $16-20$

\subsubsection{Stem colour}

Base or collar region of the main stem was considered for recording the stem colour.
1. Green
2. Grey

\subsubsection{Latex colour}

Colour of the latex was recorded on three-year-old plantations raised under uniform agronomic practises, soil and weather conditions.
1. Cream
2. Red

\subsubsection{Pigmentation of emerging leaves}

Variability in pigmentation of young emerging leaves was recorded on the tertiary branches. Colour was assigned as per the Royal Horticultural Society colour chart (Fig. 5).

1. Green (Code: $142 \mathrm{~A}$ )

2. Green-greyed purple (Code: $140 \mathrm{~A}+185 \mathrm{D}$ )

3. Yellow-green (Code: $149 \mathrm{~A}$ )

4. Greyed purple (Code: 185 A, B)

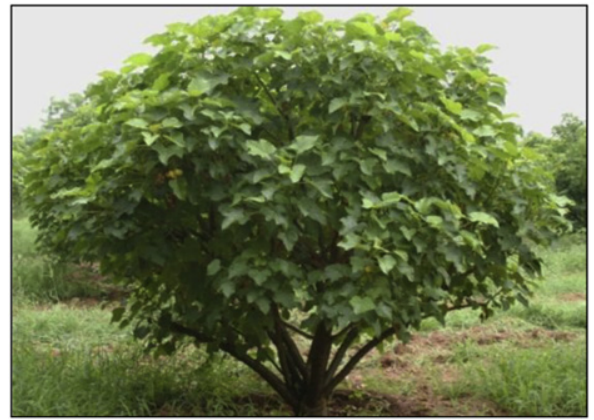

1. Abundant

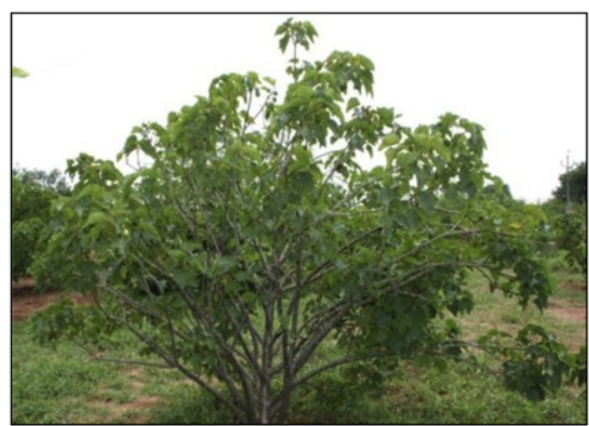

2. Moderate

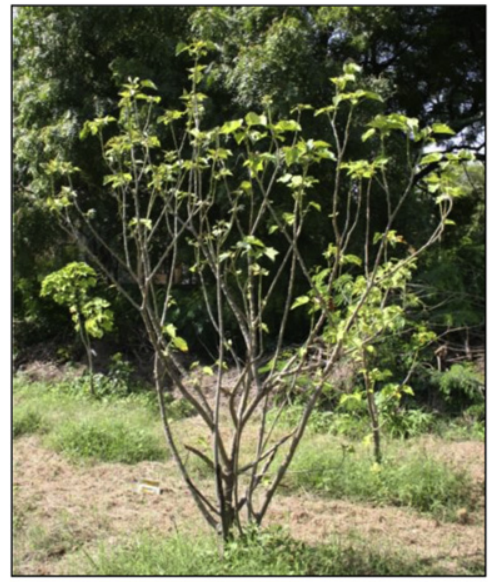

3. Scanty

Fig. 3 - Leafiness. 


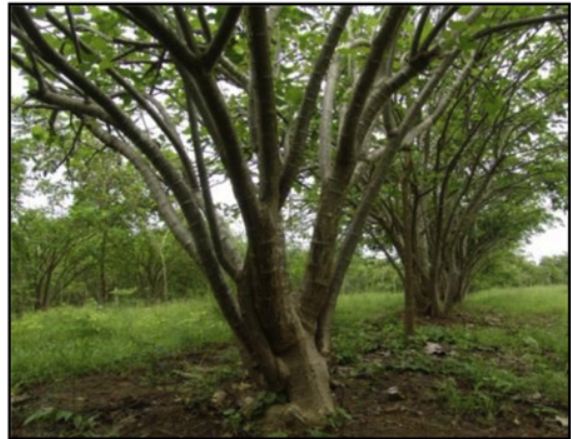

1. Basal

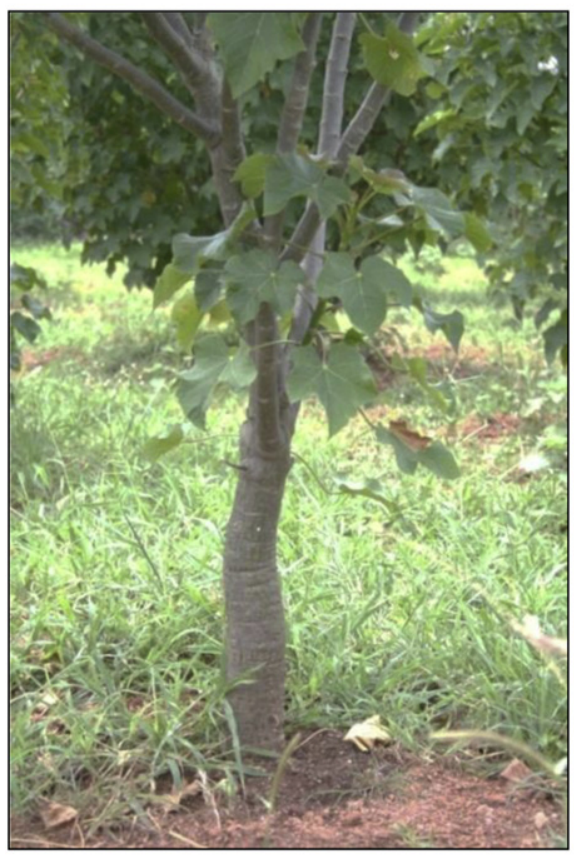

3. Top

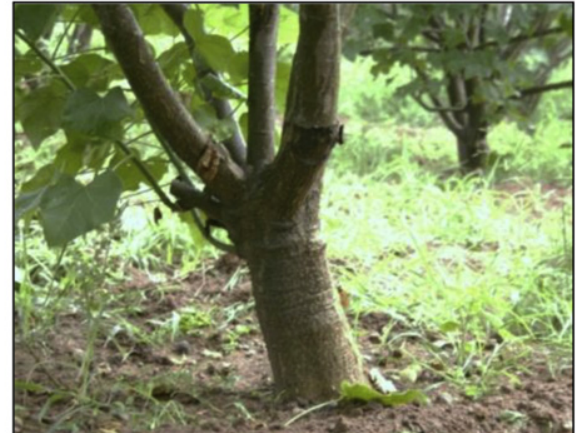

2. Intermediate

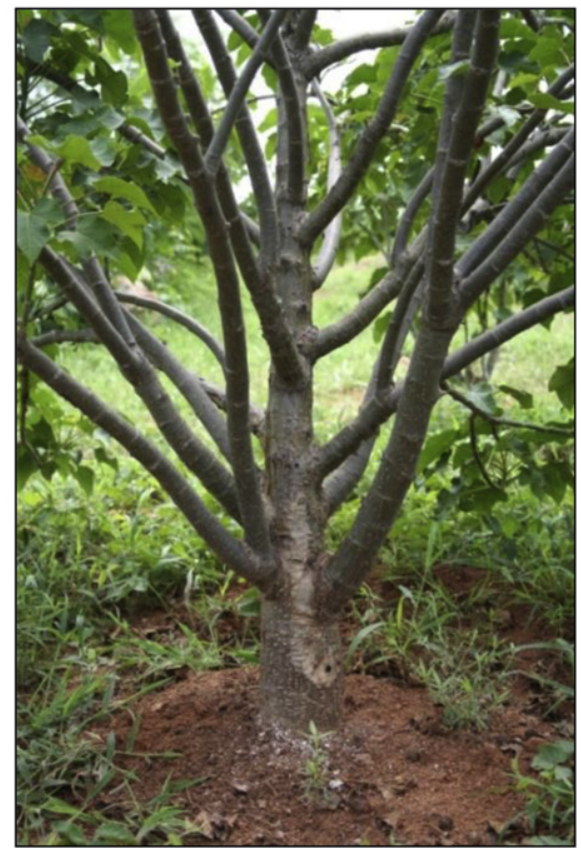

4. Entire

Fig. 4 - Branching pattern.

5. Dark greyed purple (Code: $187 \mathrm{~A}$ )

6. Red (Code: $44 \mathrm{~A}$ )

\subsubsection{Petiole base pigmentation}

It was recorded on the terminal shoots of current season growth (Fig. 6).
1. Green
2. Purple
3. Brown

\subsubsection{Leaf blade size}

The matured leaves of the tertiary branches were considered for measuring the leaf blade size.

1. Small $\left(<250 \mathrm{~cm}^{2}\right)$

2. Medium $\left(251-500 \mathrm{~cm}^{2}\right)$

3. Large $\left(>500 \mathrm{~cm}^{2}\right)$

3.1.12. Petiole length

It was recorded on the matured leaves on the tertiary branches.
1. Small $(<12 \mathrm{~cm})$

2. Medium $(12-22 \mathrm{~cm})$

3. Large $(>22 \mathrm{~cm})$

\subsubsection{Leaf colour}

Colour of leaves was recorded on mature leaves of the current season growth on the tertiary branches. Colour was assigned as per the Royal Horticultural Society colour chart.
1. Light green (140 A)
2. Green (134 A)
3. Dark green (136 A)

\subsubsection{Number of leaf lobes}

It was recorded on mature leaves of the current season growth on the tertiary branches (Fig. 7).
1. $0-2$
2. $3-5$
3. $>6$ 


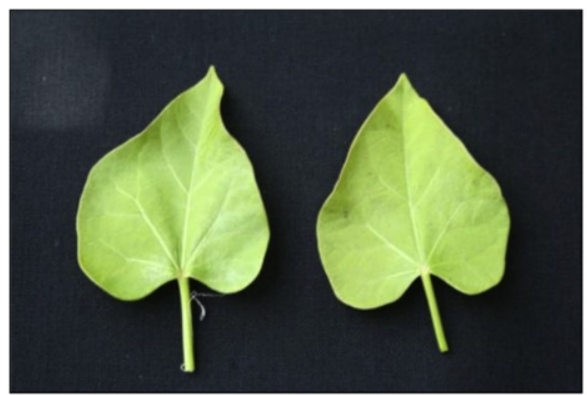

1. Green (Code: 142A)

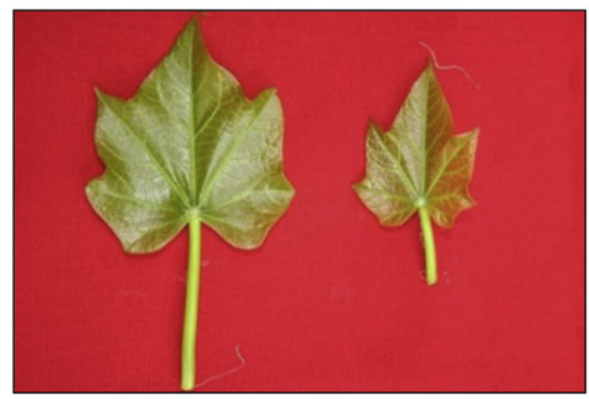

3. Yellow green (Code: 149 A)

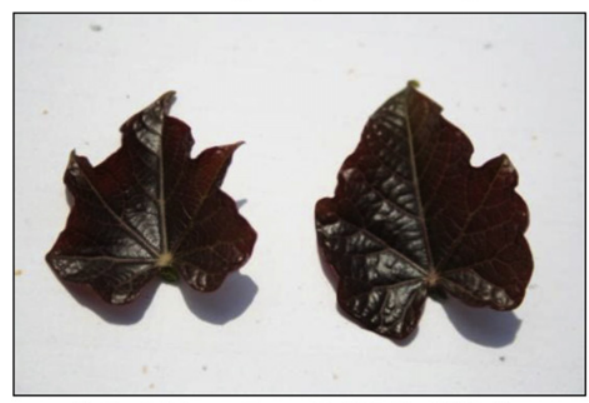

5. Dark Greyed purple (Code: $187 \mathrm{~A})$

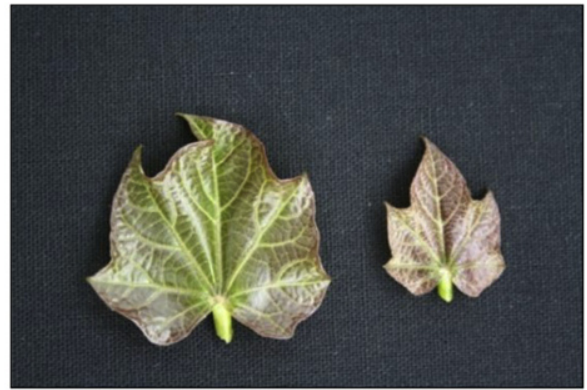

2. Green Greyed purple (Code: $140 \mathrm{~A}+185 \mathrm{D})$

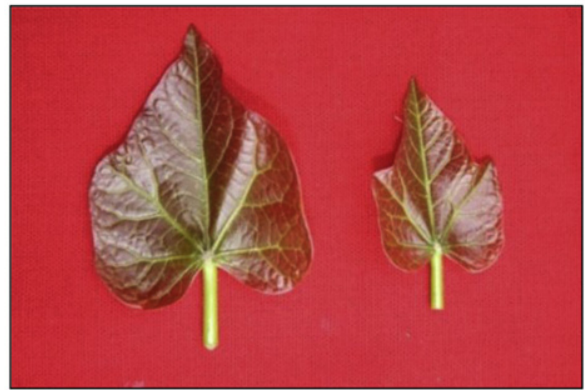

4. Greyed purple (Code: 185 A, B)

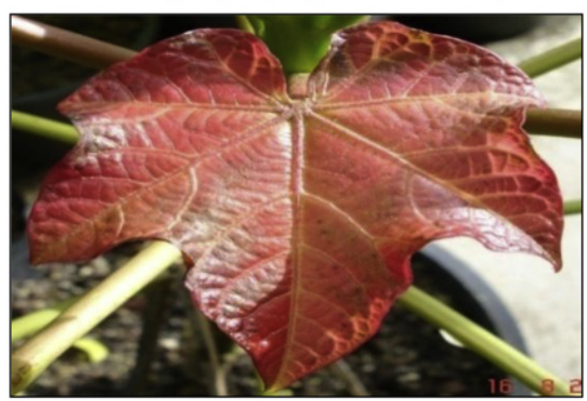

6. Red (Code: 44 A)

Fig. 5 - Pigmentation of emerging leaves.

Note: In general, number of leaf lobes varied from 0 to 6 , however, occurrence of two or three differently lobed leaves on the same plant was a common feature.

\subsubsection{Phyllotaxy}

It was recorded on young tertiary branches of current season growth.

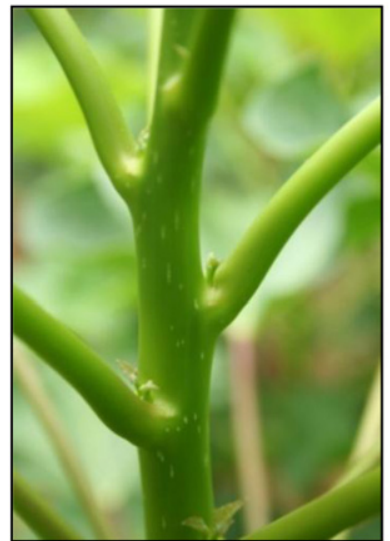

1. Green

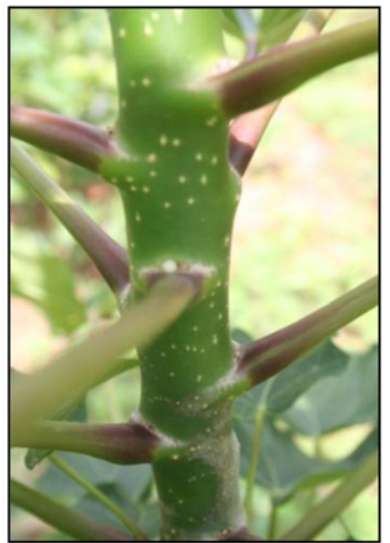

2. Purple

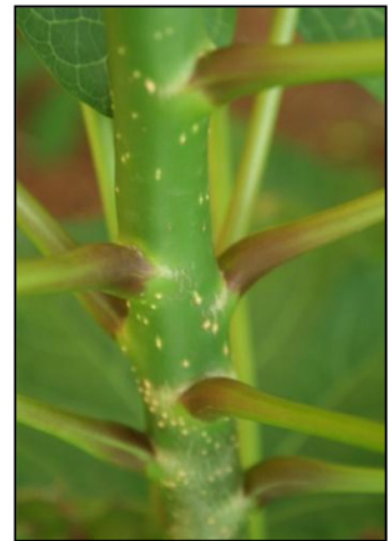

3. Brown

Fig. 6 - Petiole base pigmentation. 


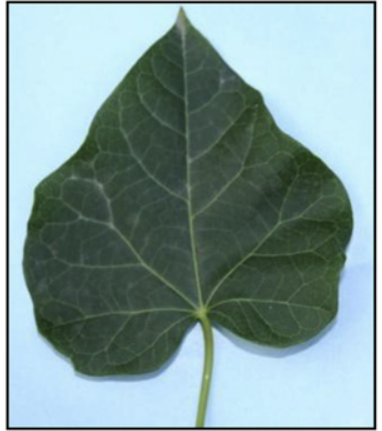

1. Zero

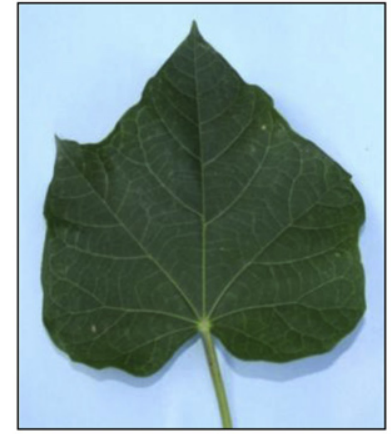

2. One

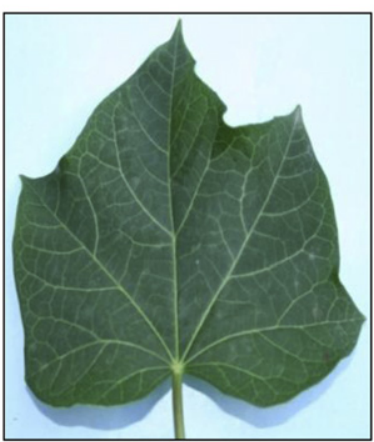

4. Three

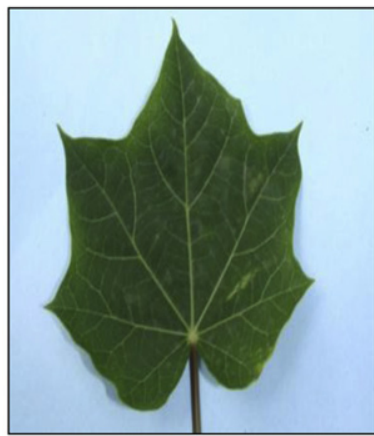

5. Four

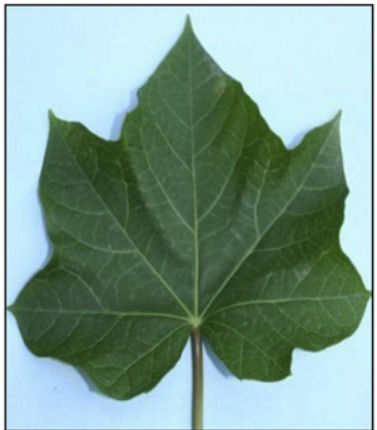

6. Five

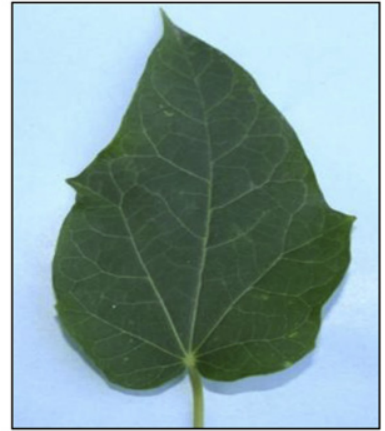

3. Two
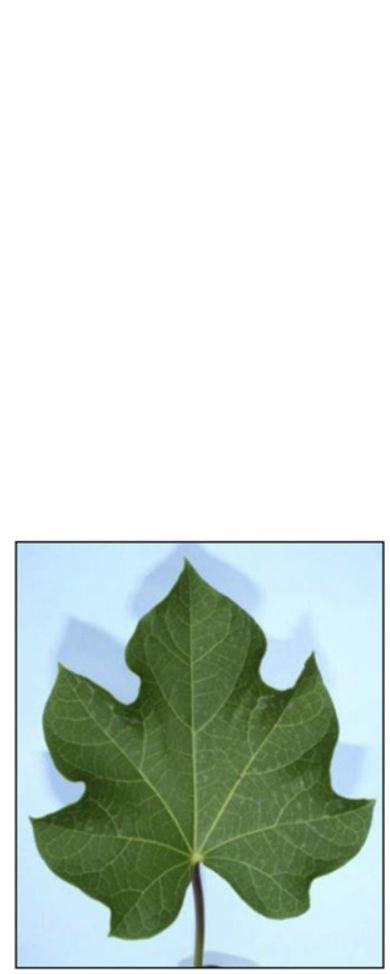

7. Six

Fig. 7 - Number of leaf lobes.

1. Whorled

2. Alternate

3.1.16. Leaf angle with main stem

It was recorded on young tertiary branches of current season growth.

1. $0-45^{\circ}$

2. $15^{\circ}-45^{\circ}$

3. $>45^{\circ}$

3.1.17. Inflorescence

It was recorded on young tertiary branches of current season growth.

1. Axillary

2. Terminal

3.1.18. Peduncle length

It was recorded on the inflorescence of the tertiary (terminal) branches on the current season growth (Fig. 8).
1. $0-5 \mathrm{~cm}$

2. $>5 \mathrm{~cm}$

\subsubsection{Inflorescence compactness}

It was recorded at same growth stage of the inflorescence as being depicted in Fig. 9.
1. Loose
2. Semi-loose
3. Compact
4. V. Compact.

\subsubsection{Flower colour}

It was recorded on fully expressed inflorescence.
1. Cream yellow
2. White
3. Other 


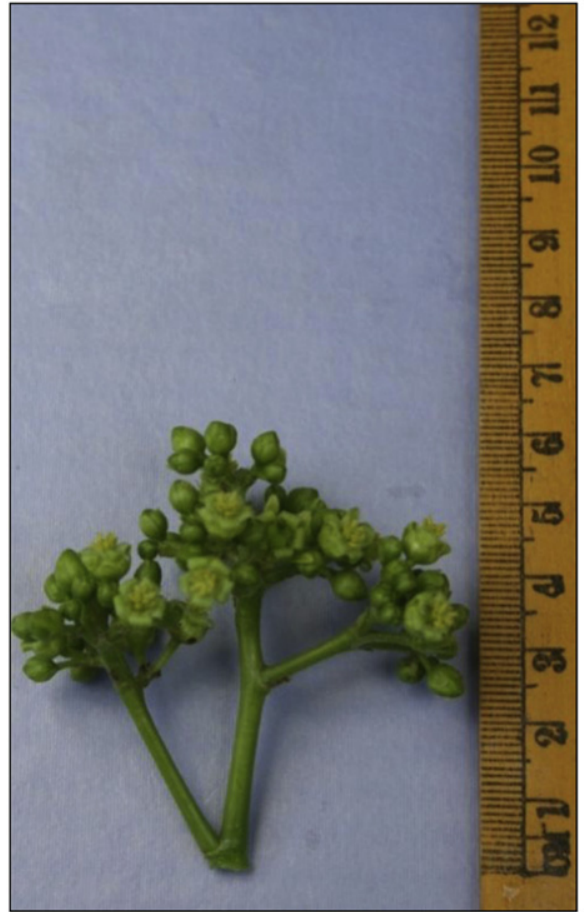

1. $0-5 \mathrm{~cm}$

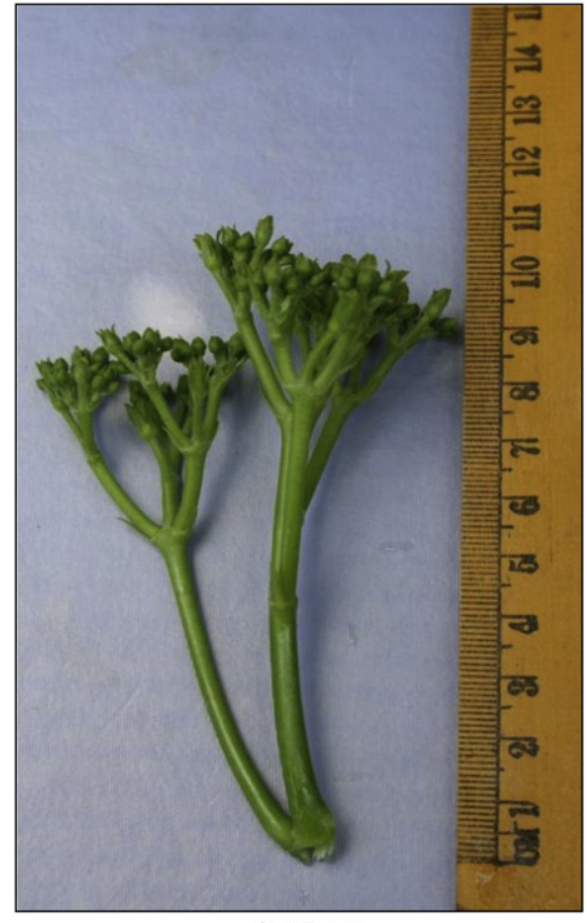

2. $>5 \mathrm{~cm}$

Fig. 8 - Peduncle length (cm).

\subsubsection{Size of female flower}

It was recorded on the fully opened female flowers.
1. Small $(<10 \mathrm{~mm})$
2. Large $(>10 \mathrm{~mm})$

3.1.22. Size of male flower

It was recorded on the fully opened male flowers.

$$
\begin{aligned}
& \text { 1. Small }(<5 \mathrm{~mm}) \\
& \text { 2. Large }(>5 \mathrm{~mm})
\end{aligned}
$$

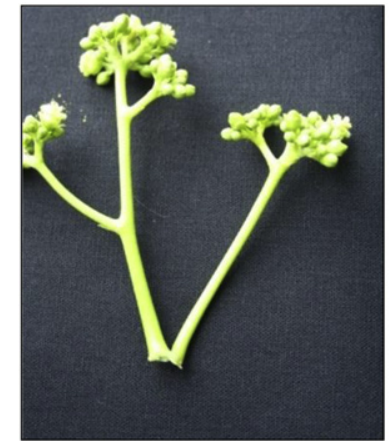

2. Semi-loose

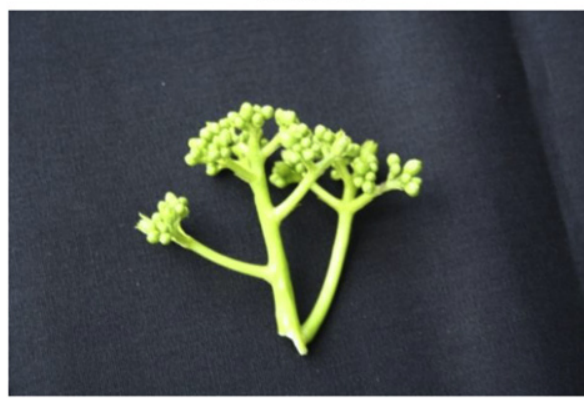

3. Compact

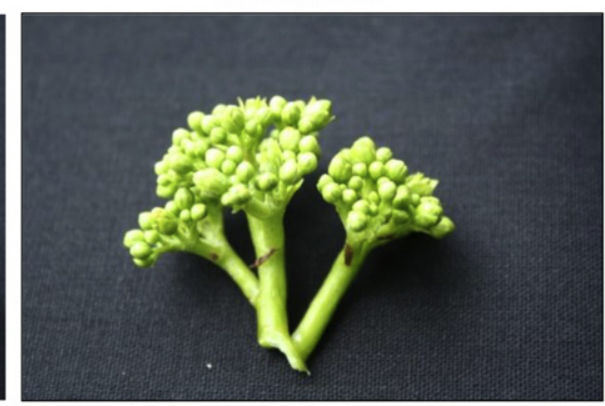

4. Very compact

Fig. 9 - Inflorescence compactness. 
3.1.23. Female:male flower ratio

The female and male flower ratio was recorded on the fully expressed inflorescence (Fig. 10).

1. $<1: 10$

2. $1: 11-20$

3. $1:>20$

\subsubsection{Inflorescence abundance}

Recorded on three-year-old plantations raised under uniform agronomic practises, soil and weather conditions.

1. Poor

2. Average

3. Abundant

3.1.25. Flowering

1. One flush

2. Two flushes

3. Continuous flushes

3.1.26. Length of fruit stalk

It was recorded on fruits at maturity stage.

1. Small $(<4 \mathrm{~cm})$

2. Medium $(4-7 \mathrm{~cm})$

3. Large $(>7 \mathrm{~cm})$

3.1.27. Number of fruits per cluster

Recorded on fruit clusters during peak podding stage.

1. $0-5$

2. $6-10$

3. $11-15$

4. $>15$
3.1.28. Average number of seeds/fruit Recorded on healthy and mature pods.

1. $<3$

2. 3

3. $>3$

3.1.29. Pod length $(\mathrm{cm})$

Recorded as a mean of 100 physiologically mature pods.

1. $<2 \mathrm{~cm}$
2. $>2 \mathrm{~cm}$

3.1.30. Pod width $(\mathrm{cm})$

Recorded as a mean of 100 physiologically mature pods.

1. $<1.8 \mathrm{~cm}$

2. $>1.8 \mathrm{~cm}$

3.1.31. Pod breadth $(\mathrm{cm})$

Recorded as a mean of 100 physiologically mature pods.

1. $<1.8 \mathrm{~cm}$

2. $>1.8 \mathrm{~cm}$

3.1.32. Seed length $(\mathrm{cm})$

Recorded as a mean of 100 physiologically mature pods.

1. $<1.8 \mathrm{~cm}$

2. $>1.8 \mathrm{~cm}$

3.1.33. Seed width ( $\mathrm{cm}$ )

Recorded as a mean of 100 physiologically mature pods.

1. $<0.9 \mathrm{~cm}$

2. $>0.9 \mathrm{~cm}$

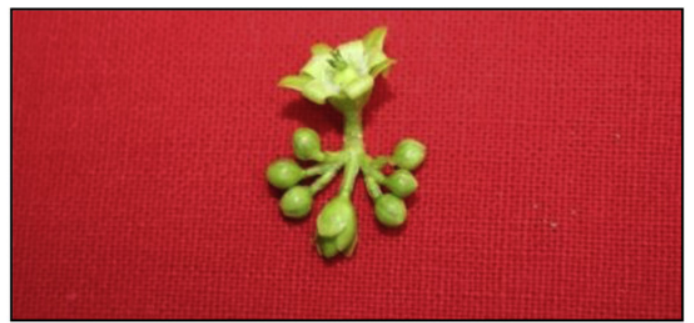

1. 1: 10

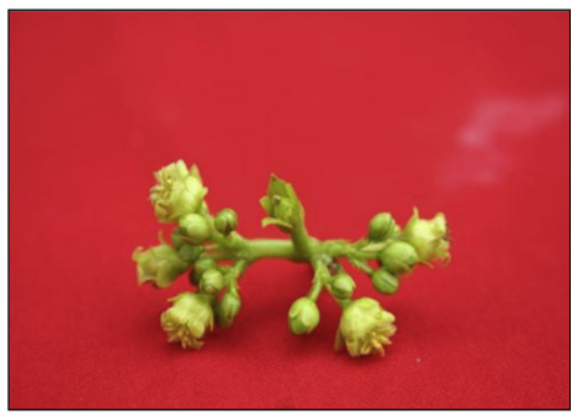

2. 1: $11-20$

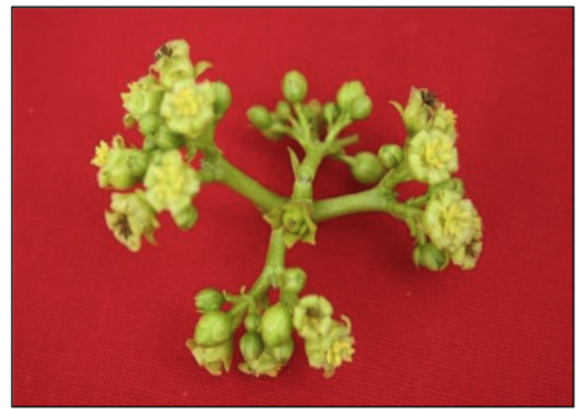

3. $1:>20$

Fig. 10 - Female:male flower ratio. 


\subsubsection{Seed breadth $(\mathrm{cm})$}

Recorded as a mean of 100 physiologically mature pods.

$$
\text { 1. }<1.1 \mathrm{~cm}
$$$$
\text { 2. }>1.1 \mathrm{~cm}
$$

\subsubsection{0-seed weight ( $g$ )}

Recorded on fully mature and dried seed.

\subsubsection{Seed surface}

Recorded on physiologically mature seed.
1. Rough
2. Smooth
3. Shiny

\subsubsection{Fruit shape}

Recorded on physiologically matured fruits.

1. Oval

2. Round

\subsubsection{Oil content}

Seed oil content was analysed by Soxhlet method.

\author{
1. Low (0-20\%) \\ 2. Medium (21-30\%) \\ 3. High (31-40) \\ 4. $(>40 \%)$
}

The J. curcas germplasm used in the study exhibited adequate variability for both quantitative and qualitative traits. The variability in the 38 traits was recorded and documented by developing the relevant descriptors and descriptor states.

Some of the plant traits such as plant canopy, branching habit, number of primary branches, peduncle branching, peduncle length, inflorescence compactness, flower ratio, inflorescence abundance, flowering, fruits per cluster, 100-seed weight and oil content may directly influence the yield of the plants. The male to female ratio observed in the present study ranged from 10:1 to $>20: 1$. Dhillon et al. [2] also reported an average male to female ratio of 20:1 which changed to $108: 1$ when the temperatures fell. Decrease in the male to female flower ratio over the first and second years from 25:1 to 13:1 was observed and reported as a positive trend towards enhanced productivity [3]. In this study, the oil content ranged from 17.5 to $41.6 \%$ and the descriptor has been categorized accordingly as 0-20, 21-30, $30-40$ and $\geq 40 \%$. The existence of wide variation is an indication of existence of genotypic variation apart from the influence of the environment in the surveyed region. Wide variation in oil content such as, $27.8-38.4 \%$, 28-39\%, 30-37\% among the Indian accessions has been reported [4-6] respectively.

Some traits viz., growth habit, leafiness, branching pattern, leaf blade size, petiole length, phyllotaxy, leaf angle with the main stem, flower size, length of fruit stalk, average number of seeds per fruit, pod length, pod breadth, pod width, seed length, breadth, width and fruit shape may contribute to yield in an indirect manner.

Traits viz., stem colour, latex colour, pigmentation of the emerging leaves, petiole base pigmentation, leaf colour, number of leaf lobes and seed surface may act as morphological markers. In the present study, good variation in the morphological markers viz., stem colour (green and grey), latex colour (cream and red), pigmentation of the young emerging leaves (green, green-greyed purple, yellow-green, greyed purple, dark greyed purple and red), petiole base pigmentation (green, purple and brown), leaf colour (light green, green and dark green), number of leaf lobes (1-6) and seed surface (rough, smooth and shiny) was observed. More than 1000 morphological markers have been identified in barley [7]. Smiryaev and Bocharnikova [8] proposed a genetic statistical method of estimation of intraspecific diversity by morphological genes in cultivated crops.

The developed descriptors and descriptor states are based on a technical bulletin in Ref. [9] on "Developing Crop Descriptors Lists" wherein "The Concept of Descriptor" "Descriptors and Derived Standards" and "Crop Specific Descriptors" etc., have been detailed. Similar efforts to develop descriptors were made for cereals and related crops [10], vegetable crops [11], fruit crops including tropical and sub-tropical fruit trees [12] and for medicinal and aromatic plants [13]. Terry and Lauren [14] developed descriptors for guayule (Parthenium argentatum Gray) and Sunil et al. [15] developed a set of pictorial descriptors for J. curcas based on the germplasm collected from all over India which is the first report at development of descriptors for Jatropha. The development of descriptors is among the first systematic efforts to record the diversity in a plant species. The methodical documentation of diversity greatly enhances the utilization of the germplasm. The qualitative traits help as morphological markers and serve as resource guide in identification of useful germplasm lines in a short period. The development of descriptors in a perennial and highly potential biodiesel species like Jatropha will lead to effective utilization of the germplasm in the crop improvement programmes.

\section{Acknowledgements}

The authors are thankful to the Director, NBPGR, New Delhi; Director, CRIDA, Hyderabad; Head, Plant Quarantine Division, NBPGR, New Delhi and Director, DOR for continued support and facilities for the present study. The financial support of the RSAD, Government of Andhra Pradesh for the above study is gratefully acknowledged.

\section{R E F E R E N C E S}

[1] Sunil N, Sujatha M, Kumar Vinod, Vanaja M, Basha SD, Varaprasad KS. Correlating the phenotypic and molecular diversity in Jatropha curcas L. Biomass Bioenerg 2011;35(3): 1085-96.

[2] Dhillon RS, Hooda MS, Pundeer JS, Ahlawat KS, Kumari S. Development of efficient techniques for clonal multiplication of Jatropha curcas L., a potential biodiesel plant. Curr Sci 2009; 96:823-7.

[3] Prakash AR, Patolia JS, Chikara J, Boricha GN. Floral biology and flowering behaviour of Jatropha curcas. In: Expert seminar on Jatropha curcas L. agronomy and genetics; 2007 
March 26-28. Wageningen, The Netherlands: FACT Foundation; 2007.

[4] Wani SP, Osman M, D'Silva E, Sreedevi TK. Improved livelihoods and environmental protection through biodiesel plantations in Asia. Asian Biotechnol Dev Rev 2006;8:11-29.

[5] Kaushik N, Kumar K, Kumar S, Kaushik N, Roy S. Genetic variability and divergence studies in seed traits and oil content of Jatropha (Jatropha curcas L.) accessions. Biomass Bioenerg 2007;31:497-502.

[6] Rao GR, Korwar GR, Shanker AK, Ramakrishna YS. Genetic associations, variability and diversity in seed characters, growth, reproductive phenology and yield in Jatropha curcas (L.) accessions. Trees-struct Funct 2008;22:697-709.

[7] GrainGenes 2.0 [database on the Internet] Washington DC: US Department of Agriculture, Agricultural Research Service; 2012-[cited 2012 Nov 11] Barley Blvd, barley genetics newsletter, vol. 32 toc; Available from: http://wheat.pw.usda. gov/ [files updated monthly].

[8] Smiryaev AV, Bocharnikova NI. Estimation of morphological marker diversity. Russ J Genet 2002;38:837-42.

[9] Bioversity International. Guidelines for the development of crop descriptor lists. In: Bioversity technical bulletin series. Rome: Bioversity International; 2007.
[10] Mahajan RK, Sapra RL, Srivastava U, Mahendra Singh, Sharma GD. Minimal descriptors for characterization and evaluation of agri-horticultural crops (Part I). New Delhi: National Bureau of Plant Genetic Resources; 2000.

[11] Srivastava U, Mahajan RK, Gangopadhyay, Mahendra Singh, Dhillon BS. Minimal descriptors of agri-horticultural crops. Part II: vegetable crops. New Delhi: National Bureau of Plant Genetic Resources; 2001.

[12] Mahajan RK, Gangopadhyay KK, Gunjeet Kumar, Dobhal VK, Srivastava U, Gupta PN, et al. Minimal descriptors of agrihorticultural crops. Part III: fruit crops. New Delhi: National Bureau of Plant Genetic Resources; 2002.

[13] Singh BM, Mahajan RK, Srivastava U, Pareek SK. Minimal descriptors of agri-horticultural crops. Part IV: medicinal and aromatic plants. New Delhi: National Bureau of Plant Genetic Resources; 2003.

[14] Terry C, Lauren J. A set of descriptors for evaluating guayule germplasm. Ind Crop Prod 2011;34:252-5.

[15] Sunil N, Vinod Kumar, Varaprasad KS, Rajeshwara GR, Sujatha M, Sharma SK. Minimal descriptors of Jatropha curcas L. New Delhi: National Bureau of Plant Genetic Resources; 2010. 